\title{
Níveis de Proteína Bruta em Rações para Suínos Machos Castrados em Fase Inicial de Crescimento, Mantidos em Ambiente de Baixa Temperatura ${ }^{1}$
}

\author{
Edilson Paes Saraiva ${ }^{2}$, Rita Flávia Miranda de Oliveira $^{3}$, Juarez Lopes Donzele ${ }^{3}$, \\ Aloízio Soares Ferreira ${ }^{3}$, Rony Antonio Ferreira ${ }^{2}$, Wilkson Oliveira Rezende ${ }^{4}$, \\ Uislei Antonio Dias Orlando ${ }^{2}$, Roberta Gomes Marçal Vieira Vaz ${ }^{5}$
}

\begin{abstract}
RESUMO - Objetivando-se avaliar níveis de proteína bruta da ração para suínos machos castrados em fase inicial de crescimento, mantidos em ambiente de baixa temperatura $\left(15^{\circ} \mathrm{C}\right)$, foram utilizados 60 suínos mestiços (Landrace x Large White), com peso inicial médio de $15,1 \pm 0,50 \mathrm{~kg}$ e idade média de $56 \pm 3,6$ dias. Os animais foram distribuídos em delineamento experimental de blocos ao acaso, com cinco tratamentos, seis repetições e dois animais por unidade experimental. Os tratamentos foram constituídos de rações com 17,0; 18,0; 19,0; 20,0 e 21\% de proteína bruta (PB). Os níveis de PB da ração influenciaram o ganho de peso diário, que aumentou de forma quadrática até o nível de 19,6\%. A conversão alimentar também variou de forma quadrática, melhorando até o nível de $20 \%$. Os consumos de ração e de energia digestível diários não foram influenciados pelos tratamentos. O ajuste dos dados pelo modelo LRP indicou como nível adequado $20 \%$ de PB, a partir do qual os dados permaneceram em um platô. Os tratamentos influenciaram a taxa de deposição de proteína, que aumentou de forma linear, enquanto a de gordura não variou. Concluiu-se que o nível de $20 \%$ de PB da ração, associado a um consumo de 10,7 g de lisina diário, promove os melhores resultados de desempenho para suínos machos castrados de 15 a $30 \mathrm{~kg}$, mantidos em ambiente de baixa temperatura.
\end{abstract}

Palavras-chave: desempenho, frio, leitões, machos castrados, níveis de proteína

\section{Crude Protein Levels in Diets for Barrows in the Initial Growing Phase, under Low Temperature Environment}

\begin{abstract}
Sixty crossbred piglets, with average initial weight of $15.1 \pm 0.50 \mathrm{~kg}$ and $56 \pm 3.6$ days old were used to evaluate the dietary crude protein levels, for barrows in the initial growing phase, under low temperature environment $\left(15^{\circ} \mathrm{C}\right)$. The animals were allotted to a randomized blocks design, with five treatments, six replications and two animals per experimental unit. The treatments consisted of diets with 17.0, 18.0, 19.0, 20.0, and 21.0\% crude protein (CP). The dietary crude protein levels affected daily weight gain, that increased in a quadratic way up to $19.6 \%$. Feed:gain ratio also changed in a quadratic way, increasing up to $20.0 \%$. Daily feed and digestible energy intakes were not influenced by the treatments. The best fit was obtained with the LRP discontinuous model, which estimated the crude protein level at $20 \%$, when the data reached a plateau. The treatments influenced the protein deposition rate, that increased linearly, while the fat deposition rate did not change. It was concluded that the dietary crude protein level of $20.0 \%$, associated to a daily intake of $10.7 \mathrm{~g}$ total lysine, showed the best results of performance for barrows from 15 to $30 \mathrm{~kg}$, under low temperature environment.
\end{abstract}

Key Words: males barrows, cold, performance, piglets, protein levels

\section{Introdução}

As exigências nutricionais dos suínos devem ser estabelecidas para as diferentes fases de desenvolvimento e também para os diferentes ambientes aos quais são submetidos, uma vez que o ambiente térmico pode influenciar o consumo voluntário e a composição de ganho (Schenck et al., 1992).

Os suínos, como animais homeotérmicos, podem apresentar seu máximo potencial genético quando se encontram na zona de conforto térmico (temperatura ótima). A zona de conforto térmico compreende a faixa de temperatura ambiente efetiva, na qual o calor produzido durante os processos de mantença e produção é igual ao calor perdido para o ambiente térmico, sem aumento da produção de calor metabólico. O conforto térmico é dependente de diversos fatores, alguns ligados ao animal, como: peso, idade,

\footnotetext{
${ }_{1}^{1}$ Parte da Tese de Mestrado do primeiro autor. Projeto financiado pela FAPEMIG.

${ }^{2}$ Estudante de Doutorado do DZO/UFV, E-mail: edpsaraiva@mailcity.com; ronyferreira@hotmail.com; uislei@lycos.com

3 Professor(a) do DZO/UFV. E.mail: flavia@mail.ufv.br; donzele@mail.ufv.br

${ }^{4}$ Estudante de Zootecnia - DZO/UFV

${ }^{5}$ Estudante de Mestrado do DZO/UFV. Email: robertavaz@lycos.com
} 
estado fisiológico, tamanho do grupo, nível de alimentação e genética; e outros ligados ao ambiente como: temperatura, velocidade do vento, umidade relativa, tipo de piso e energia radiante. A temperatura ideal para suínos entre 20 e $30 \mathrm{~kg}$ está entre 18 e $20^{\circ} \mathrm{C}$ (Hannas, 1999a).

Em condições de baixa temperatura, o aumento do consumo de alimentos é um recurso que o animal utiliza para elevar a produção de calor metabólico e manter a homeotermia (Fialho \& Cline, 1994). Por outro lado, a alimentação representa grande parte do custo total de produção e a proteína é o nutriente mais oneroso das rações de suínos no Brasil. Do ponto de vista prático, é importante estabelecer níveis adequados de proteína para cada fase do ciclo de produção. Da mesma forma, é importante considerar as condições do ambiente para se adequar as necessidades nutricionais dos animais.

O aumento da eficiência na produção se suínos, entre outros fatores, é obtido em condições desejáveis de alojamento e ambiente térmico. Considerar a interação entre níveis de alimentação e condições térmicas é importante, uma vez que esta pode comprometer a energia disponível para produção e os ganhos energéticos podem ser modificados (Verstegen \& De Greef, 1992).

A temperatura ambiente pode influenciar, além do desempenho, a composição do ganho. Tem-se verificado que tanto a temperatura ambiente quanto os níveis de proteína da dieta alteram a taxa de deposição diária de gordura e proteína na carcaça dos suínos (Ferguson \& Gous, 1997). Os níveis inadequados de proteína, além de aumentarem a produção de calor, podem influenciar as necessidades de mantença dos animais em razão, principalmente, do aumento da perda de nitrogênio na urina, como conseqüência do desvio metabólico no ciclo da uréia.

Este trabalho foi conduzido para avaliar níveis de proteína bruta em rações de suínos na fase inicial de crescimento (15 aos $30 \mathrm{~kg}$ ), mantidos em ambiente de baixa temperatura $\left(15^{\circ} \mathrm{C}\right)$.

\section{Material e Métodos}

O experimento foi conduzido no Setor de Suinocultura do Departamento de Zootecnia do Centro de Ciências Agrárias da Universidade federal de Viçosa, em Viçosa, MG.

Foram utilizados 60 suínos mestiços (Landrace $\mathrm{x}$ Large White), machos castrados, em fase inicial de crescimento, com idade de $56,5 \pm 3,6$ dias e peso inicial de $15,1 \pm 0,50 \mathrm{~kg}$, distribuídos em delineamento experimental de blocos ao acaso, com cinco tratamentos $(17,0 ; 18,0 ; 19,0 ; 20,0$ e $21,0 \%$ de proteína bruta na ração), seis repetições e dois animais por repetição. $\mathrm{Na}$ formação dos blocos, foram considerados o peso inicial, a idade e o parentesco dos animais.

Os animais, em grupo de dois, foram alojados em baias metálicas suspensas $(1,65 \times 1,10 \mathrm{~m})$, com piso ripado, providas de comedouro semi-automático e bebedouro tipo chupeta, mantidos em sala de alvenaria com janelas de vidro do tipo basculante, com cobertura de telha de barro e forro de madeira.

A temperatura no interior da sala foi mantida por meio de dois aparelhos de ar condicionado, com potência total de $60.000 \mathrm{BTU}$, ambos ligados a um termostato regulado para a temperatura de $15^{\circ} \mathrm{C}$. Os equipamentos de medição ambiental (termômetros de máxima e mínima, de bulbo seco e bulbo úmido e de globo negro) foram mantidos em uma gaiola vazia, no centro da sala, a meia altura do corpo dos animais. A temperatura e a umidade relativa interna da sala foram monitoradas diariamente e as leituras efetuadas três vezes ao dia $(8,13$ e $17 \mathrm{~h})$. Os valores obtidos foram, posteriormente, convertidos no índice de temperatura de globo e umidade (ITGU), segundo Buffington et al. (1981), caracterizando o ambiente térmico no qual os animais foram mantidos.

As rações experimentais, cujas composições centesimais e calculadas encontram-se na Tabela 1 , foram preparadas à base de milho, farelo de soja e glúten de milho e formuladas para satisfazerem as exigências dos animais em energia, minerais e vitaminas, de acordo com Rostagno et al. (1992). Os níveis de proteína bruta $(\mathrm{PB})$ das rações foram obtidos por meio da variação proporcional nas quantidades de milho, farelo de soja e glúten de milho, corrigindo-se, também, o nível de energia pela variação nas quantidades de amido e areia lavada (material inerte). As rações foram isoenergéticas e os aminoácidos variaram de acordo com o nível de proteína, mantendo-se a proporcionalidade com a lisina, nos diferentes níveis protéicos. Na determinação dos aminoácidos digestíveis dos ingredientes utilizados, foram aplicados os coeficientes de digestibilidade propostos nas tabelas da Rhodimet ... (1993).

As rações e a água foram fornecidas à vontade aos animais. Para determinação do consumo, as sobras de ração do chão foram coletadas diariamente e pesadas com as sobras do comedouro no final do 
Tabela 1 - Composições centesimais e calculadas das rações experimentais

Table 1 - Centesimal and calculated composition of the experimental diets

\begin{tabular}{|c|c|c|c|c|c|}
\hline \multirow[t]{2}{*}{$\begin{array}{l}\text { Ingredientes }(\%) \\
\text { Ingredients }\end{array}$} & \multicolumn{5}{|c|}{$\begin{array}{c}\text { Níveis de proteína bruta }(\%) \\
\text { Crude protein levels }\end{array}$} \\
\hline & 17 & 18 & 19 & 20 & 21 \\
\hline Milho (Corn) & 48,19 & 51,02 & 53,85 & 56,69 & 59,52 \\
\hline Farelo de soja (Soybean meal) & 22,29 & 23,60 & 24,91 & 26,22 & 27,53 \\
\hline Glúten (Gluten) & 5,73 & 6,07 & 6,40 & 6,74 & 7,08 \\
\hline Amido (Corn starch) & 17,72 & 13,47 & 9,20 & 4,91 & 0,64 \\
\hline Fosfato bicálcico (Dicalcium phosphate) & 1,91 & 1,83 & 1,76 & 1,68 & 1,60 \\
\hline Calcário (Limestone) & 0,69 & 0,72 & 0,76 & 0,79 & 0,82 \\
\hline Mistura mineral (Mineral mix) ${ }^{1}$ & 0,10 & 0,10 & 0,10 & 0,10 & 0,10 \\
\hline Mistura vitamínica (Vitamin mix) ${ }^{2}$ & 0,10 & 0,10 & 0,10 & 0,10 & 0,10 \\
\hline Sal comum (Salt) & 0,30 & 0,29 & 0,29 & 0,28 & 0,28 \\
\hline BHT (Antioxidant) & 0,01 & 0,01 & 0,01 & 0,01 & 0,01 \\
\hline Óleo de soja (Soybean oil) & 1,85 & 1,85 & 1,85 & 1,85 & 1,85 \\
\hline Areia lavada (Washed sand) & 1,11 & 0,93 & 0,77 & 0,63 & 0,46 \\
\hline TOTAL & 100,00 & 100,00 & 100,00 & 100,00 & 100,00 \\
\hline \multicolumn{6}{|l|}{ Composição calculada (Calculated composition) } \\
\hline Proteína bruta (Crude protein) $(\%)$ & 17 & 18 & 19 & 20 & 21 \\
\hline $\mathrm{ED}(\mathrm{kcal} / \mathrm{kg})$ & 3.500 & 3.500 & 3.500 & 3.500 & 3.500 \\
\hline Lisina (Lysine) $(\%)$ & 0,78 & 0,83 & 0,87 & 0,92 & 0,96 \\
\hline Lisina digestível (Digestible lysine) (\%) & 0,67 & 0,71 & 0,75 & 0,79 & 0,83 \\
\hline Relação lisina:proteína (\%) (Lysine:protein ratio) & 4,6 & 4,6 & 4,6 & 4,6 & 4,6 \\
\hline Relação tre. dig.:lisina dig. (\%) (Dig. Thr:dig. Lys. Ratio) & 80,8 & 80,8 & 80,8 & 80,8 & 80,8 \\
\hline Relação met. dig.:lisina dig. (\%) (Dig. Met:dig. Lys ratio) & 40,4 & 40,4 & 40,4 & 40,4 & 40,4 \\
\hline Cálcio (Calcium) (\%) & 0,80 & 0,80 & 0,80 & 0,80 & 0,80 \\
\hline Fósforo total (Total phosphorus) (\%) & 0,60 & 0,60 & 0,60 & 0,60 & 0,60 \\
\hline
\end{tabular}

${ }_{1}^{1}$ Contém em $1 \mathrm{~kg}$ (Content/kg): Fe, 100 g; Cu, 10 g; Co, 1 g; Mn, 40 g; Zn, 100 g; I, 1,5 g; e excipiente (excipient) q.s.p., 1000 g.

2 Contém em $1 \mathrm{~kg}$ (Conten/kg): vitamina A, 6.000.000 UI; vitamina $D_{3}, 1.500 .000$ UI; vitamina $E, 15.000 .000$ UI; vitamina $B_{1}, 1,35$ g; vitamina $\mathrm{B}_{2}, 4 \mathrm{~g}$; vitamina $\mathrm{B}_{6}, 2 \mathrm{~g}$; ácido pantotênico (Pantothenic acid), 9,35 g; vitamina $\mathrm{K}_{3}, 1,5 \mathrm{~g}$; ácido nicotínico (Nicotinic acid), $20,0 \mathrm{~g} ;$ vitamina B12, 20,0 g; ácido fólico (Pholic acid), 0,6 g; biotina (Biotin), 0,08 g; Se, 0,3g; e excipiente (and excipient) q.s.p., $1000 \mathrm{~g}$.

período experimental. Os animais permaneceram no experimento até atingirem o peso de $30,4 \pm 1,90 \mathrm{~kg}$.

No final do período experimental, que durou $29,0 \pm 4,5$ dias, os animais foram submetidos a jejum alimentar de 24 horas. Após completado o período de jejum, um animal de cada unidade experimental, com o peso mais próximo de $30 \mathrm{~kg}$, foi abatido por dessensibilização e sangramento. Em seguida, procedeu-se à depilação e à retirada dos órgãos.

As carcaças inteiras (incluindo cabeça e pés), evisceradas e sem sangue, foram pesadas e cortadas longitudinalmente. A metade direita de cada carcaça foi triturada em "cutter" comercial de $30 \mathrm{HP}$ e 1.775 rpm, durante 15 minutos. Após a homogeneização do material triturado, foram retiradas amostras das carcaças e estocadas em freezer a $-12^{\circ} \mathrm{C}$. Ao se prepararem as amostras para as análises laboratoriais, em razão da alta concentração de gordura do material, procedeu-se à pré-secagem em estufa, com ventilação forçada a $\pm 60^{\circ} \mathrm{C}$, por 72 horas. Em seguida, foi realizado o pré-desengorduramento pelo méto- do a quente, em aparelho extrator do tipo "Soxhlet", por quatro horas.

As amostras pré-secadas e pré-desengorduradas foram moídas e acondicionadas em vidros para posteriores análises laboratoriais. A água e a gordura, retiradas no preparo das amostras, foram consideradas para a correção dos valores das análises subseqüentes.

As análises de proteína e extrato etéreo dos ingredientes, das rações e das amostras foram realizadas no Laboratório de Nutrição Animal do Departamento de Zootecnia da UFV, conforme metodologia descrita por Silva (1990).

Um grupo adicional de cinco leitões com peso de $15,2 \pm 0,52 \mathrm{~kg}$ foi abatido para determinação da composição da carcaça dos animais no início do experimento, seguindo o mesmo procedimento de abate dos animais utilizados no experimento.

Os valores da composição das carcaças dos leitões, no início e final do período experimental, foram utilizados para a determinação das taxas de 
deposição diárias de proteína e gordura.

As análises estatísticas das variáveis de desempenho (ganho de peso, consumo de ração e conversão alimentar), de consumo estimado de lisina e de energia digestível, bem como das taxas de deposição diárias de proteína e gordura nas carcaças foram realizadas utilizando-se o programa computacional SAEG (Sistemas de Análises Estatísticas e Genéticas), desenvolvido na Universidade Federal De Viçosa-UFV (1997).

A estimativa da exigência de proteína bruta foi feita com base nos resultados de ganho de peso, conversão alimentar, consumos de ração, lisina e energia e taxas de deposição de proteína e gordura na carcaça, utilizando-se os modelos de regressão linear, quadrática e o "Linear Response Pateau" - LRP, conforme melhor ajuste.

\section{Resultados e Discussão}

A temperatura interna da sala manteve-se, durante o período experimental, em $14,9 \pm 1,7^{\circ} \mathrm{C}$, a umidade relativa em $81 \pm 8,0 \%$, a temperatura de globo negro em $15,8 \pm 1,5^{\circ} \mathrm{C}$ e o índice de temperatura de globo e umidade (ITGU) calculado em $60,9 \pm 1,96$. A temperatura de $14,9^{\circ} \mathrm{C}$, ocorrida neste trabalho, pode ser caracterizada como uma temperatura de estresse por frio, por estar abaixo da temperatura crítica mínima $\left(17^{\circ} \mathrm{C}\right)$ para esta categoria animal, conforme estabelecido por Curtis (1983).

Os resultados de desempenho, consumos estimados de proteína, lisina e energia digestível diários e das taxas de deposição de proteína e gordura, na carcaça dos leitões dos 15 aos $30 \mathrm{~kg}$, encontram-se na Tabela 2.

Os níveis de proteína bruta $(\mathrm{PB})$ da ração influenciaram $(\mathrm{P}<0,02)$ o ganho de peso diário (GPD), que aumentou de forma quadrática até o nível de 19,6\% (Figura 1). O resultado foi similar ao obtido por Hannas (1999b), que, trabalhando com leitões de 15 a $30 \mathrm{~kg}$, mantidos em ambiente termoneutro $\left(23,1^{\circ} \mathrm{C}\right)$ e recebendo ração de iguais composição e níveis protéicos, definiu como $20 \%$ a exigência de PB para maior GPD. No entanto, diferiu do valor de $21 \%$, encontrado por este mesmo autor, para animais nesta

Tabela 2 - Desempenho, consumos de lisina total e de energia digestível, relação lisina:energia e taxas de deposição de gordura e proteína na carcaça de suínos machos castrados dos 15 aos $30 \mathrm{~kg}$, alimentados com rações contendo níveis crescentes de proteína bruta e mantidos em ambiente de baixa temperatura

Table 2 - Performance, intakes of total lysine and digestible energy, energy:lysine ratio and protein and fat deposition rates in the carcass of barrows from 15 to $30 \mathrm{~kg}$ fed diets with increasing crude protein levels, under low temperature environment

\begin{tabular}{|c|c|c|c|c|c|c|}
\hline \multirow[t]{2}{*}{$\begin{array}{l}\text { Variáveis } \\
\text { Variable }\end{array}$} & \multicolumn{5}{|c|}{$\begin{array}{c}\text { Níveis de proteína bruta (\%) } \\
\text { Crude protein levels }\end{array}$} & \multirow[t]{2}{*}{$\mathrm{CV}(\%)$} \\
\hline & 17 & 18 & 19 & 20 & 21 & \\
\hline $\begin{array}{l}\text { Ganho de peso (g/dia) }{ }^{1} \\
\text { Weight gain - g/dav }\end{array}$ & 511 & 547 & 556 & 643 & 547 & 9,6 \\
\hline $\begin{array}{l}\text { Consumo de ração (g/dia) } \\
\text { Feed intake - g/day }\end{array}$ & 1167 & 1172 & 1171 & 1198 & 1132 & 8,8 \\
\hline $\begin{array}{l}\text { Consumo de ED (kcal/dia) } \\
D E \text { intake - } k c a l / d a y\end{array}$ & 4085 & 4103 & 4100 & 4194 & 3961 & 8,8 \\
\hline $\begin{array}{l}\text { Consumo de proteína }(\mathrm{g} / \mathrm{dia})^{3} \\
\text { Protein intake - g/day }{ }^{3}\end{array}$ & 198 & 211 & 223 & 240 & 238 & 8,8 \\
\hline $\begin{array}{l}\text { Consumo de lisina total }(\mathrm{g} / \mathrm{dia})^{3} \\
\text { Total lysine intake - } \mathrm{g} / \text { day }^{3}\end{array}$ & 9,12 & 9,69 & 10,23 & 11,01 & 10,92 & 8,8 \\
\hline $\begin{array}{l}\text { Conversão alimentar }{ }^{2} \\
\text { Feed:gain } \text { ratio }^{2}\end{array}$ & 2,28 & 2,16 & 2,10 & 1,87 & 2,08 & 6,7 \\
\hline $\begin{array}{l}\text { Eficiência de ED/GPD }(\mathrm{kcal} / \mathrm{g}) \\
D E / D W G \text { efficiency }\end{array}$ & 7,99 & 7,50 & 7,37 & 6,52 & 7,24 & \\
\hline $\begin{array}{l}\text { Relação energia : proteína } \\
\text { Energy:protein ratio } \\
\text { Taxas de deposição na carcaça } \\
\text { Deposition rate in the carcass }(g / \text { da }\end{array}$ & 20,63 & 19,44 & 18,38 & 17,47 & 16,62 & \\
\hline $\begin{array}{l}\text { Gordura } \\
\text { Fat }\end{array}$ & 74 & 72 & 72 & 75 & 74 & 17,0 \\
\hline $\begin{array}{l}\text { Proteína } \\
\text { Protein }\end{array}$ & 61 & 70 & 69 & 73 & 76 & 12,5 \\
\hline
\end{tabular}

1,2 Efeito quadrático $(P<0,02)$ e $(P<0,04)$, respectivamente (Quadratic effect $[P<.02]$ and $[P<.04]$, respectively).

3 Efeito linear $(P<0,01)$ (Linear effect $[P<.01]$ ). 
faixa de peso, mantidos em ambiente de calor $\left(33^{\circ} \mathrm{C}\right)$, também recebendo rações experimentais similares.

Apesar da similaridade de resultados, quanto à exigência de proteína para melhor resposta de ganho, entre os estudos com suínos mantidos em ambientes frio e termoneutro, o maior ganho de peso obtido com de $20 \%$ de PB, neste estudo (643 g), foi 3,9\% inferior ao obtido por Hannas et al. (2000), com igual nível de proteína (669 g) em ambiente termoneutro, em similar consumo de lisina. Não se observou efeito $(\mathrm{P}>0,10)$ dos tratamentos sobre o consumo de ração diário (CRD) e de energia digestível (ED) dos animais, uma vez que as rações foram isoenergéticas. Este resultado é similar àqueles observados por Edmonds et al. (1998), Hannas et al. (2000) e Orlando (2001), que não observaram variação no consumo voluntário dos suínos em fase de crescimento, sob diferentes condições ambientais, em razão do aumento da proteína dietética. $\mathrm{O}$ fato de a qualidade da proteína das rações experimentais não ter variado entre os diferentes níveis de proteína pode justificar, em parte, este resultado. De acordo com Henry \& Séve (1993), a qualidade da proteína da ração, em relação à limitação da disponibilidade de algum aminoácido essencial, pode influenciar negativamente o apetite dos suínos.

O consumo de ração médio (1168 g) observado

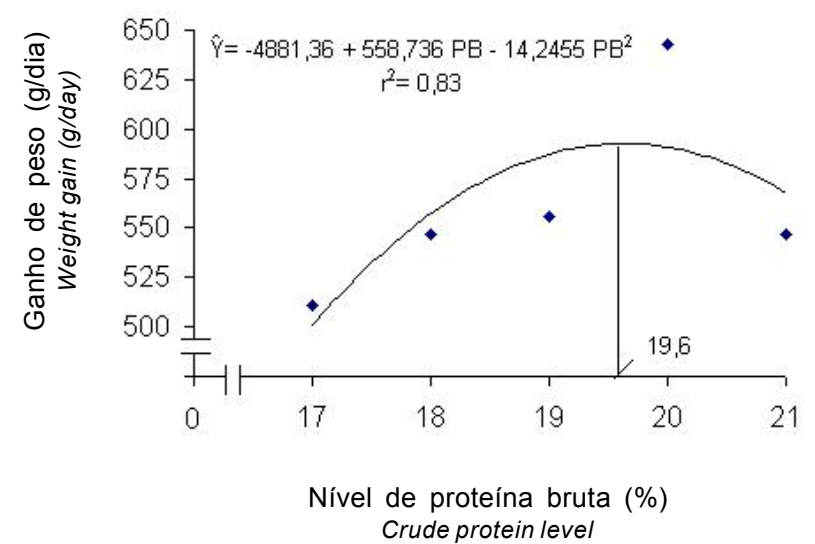

Figura 1 - Ganho de peso (g/dia) de leitões de 15 a 30 $\mathrm{kg}$, mantidos em ambiente de baixa temperatura, em função do nível de proteína da ração.

Figure 1 - Weight gain (g/day) of pigs from 15 to $30 \mathrm{~kg}$, under low temperature environment, according to the dietary crude protein level. neste estudo teve pequena variação em relação àquele de 1254 g obtido por Hannas et al. (2000), que utilizaram suínos de mesma categoria e genética em ambiente termoneutro, consumindo rações similares às usadas neste estudo. Este resultado estaria evidenciando que suínos, em fase inicial de crescimento, não são capazes de aumentar o consumo de ração em resposta ao estresse por frio. De acordo com Quiniou et al. (2000), a limitada capacidade do trato digestivo seria o motivo pelo qual os suínos não alteraram seu consumo voluntário, em resposta ao ambiente frio.

Constatou-se efeito dos níveis de proteína da ração sobre o consumo estimado de lisina total, que aumentou $(\mathrm{P}<0,01)$ de forma linear. No entanto, $\mathrm{o}$ modelo "Linear Response Plateau"- LRP foi o que melhor se ajustou aos dados, estimando em $20 \%$ o nível ótimo de proteína para maior consumo de lisina (Figura 2 ). Resultados semelhantes foram observados por Friensen et al. (1994), Souza (1997) e Hannas et al. (2000).

O nível ótimo de proteína, entre 20 e $21 \%$ de proteína, determinado pelo LRP, refletiu a redução de 5,5\% no consumo de ração. Esse resultado é um indicativo que o nível de proteína da ração não influencia o consumo voluntário de leitões entre 15 e $30 \mathrm{~kg}$.

Dessa forma, pode-se deduzir que o aumento

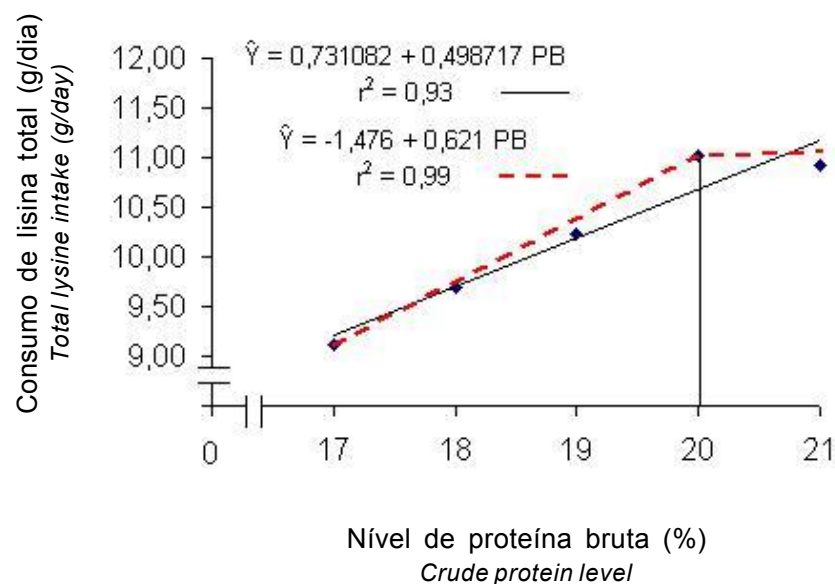

Figura 2 - Consumo estimado de lisina total (g/dia) de leitões de 15 a $30 \mathrm{~kg}$, mantidos em ambiente de baixa temperatura em função do nível de proteína da ração.

Figure 2 - Total lysine intake estimated (g/day) of pigs from 15 to $30 \mathrm{~kg}$ under low temperature environment, according to the dietary crude protein level. 
verificado no ganho de peso dos leitões, até o nível de 19,6\% de proteína, ocorreu em razão do aumento do consumo de proteína e, consequentemente, de lisina. De acordo com Noblet et al. (1987), a lisina constitui o primeiro aminoácido limitante para o ganho de peso dos suínos.

Os níveis de $\mathrm{PB}$ da ração influenciaram $(\mathrm{P}<0,04)$ a conversão alimentar (CA), que reduziu de forma quadrática até o nível de 20\% (Figura 3). Efeito positivo do aumento do nível de proteína sobre a eficiência de utilização do alimento para ganho de peso de suínos, até os $35 \mathrm{~kg}$, também foi observado por Edmonds et al. (1998) e Hannas et al. (2000). Por outro lado, Souza (1997) não constatou melhora na CA quando utilizou níveis crescentes de lisina na ração para suínos dos 15 aos $30 \mathrm{~kg}$. Efeito positivo do nível de proteína sobre a eficiência de ganho do animal também foi relatado por Fialho (1994), que destacou que o consumo de proteína abaixo da exigência dos suínos, aumenta a taxa de produção de calor metabólico, reduzindo a eficiência de utilização dos nutrientes da ração. A melhora observada na eficiência de utilização do alimento, até o nível de $20 \%$ de PB, estaria indicando uma possível alteração na composição do ganho dos animais, com

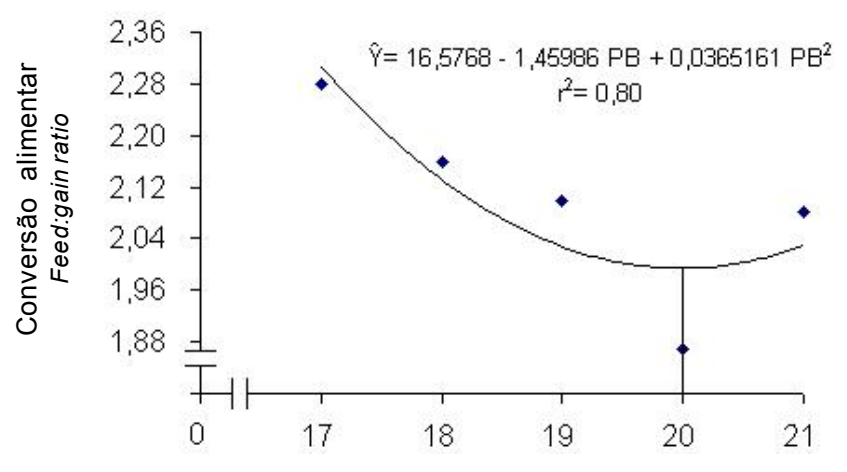

Nível de proteína bruta (\%) Crude protein level aumento na deposição de proteína na carcaça.

A piora de $11,2 \%$ observada na $\mathrm{CA}$, quando se elevou o nível de $\mathrm{PB}$ da ração de 20 para $21 \%$, pode ser um indicativo de que, quando a relação energia:proteína fica abaixo de 17,47, o consumo de energia passa a ser fator limitante para a deposição de proteína na carcaça. Neste caso, o possível gasto de energia, para degradação da proteína em excesso, reduz a eficiência de ganho do animal. Resultado semelhante foi verificado por Hannas et al. (2000), que também observaram piora na CA de suínos, na fase inicial de crescimento, entre rações em que a relação energia:proteína reduziu de 17,54 para 16,68. Berschauer et al. (1983) e Kyriazakis \& Emmans (1992) também relacionaram as melhoras de desempenho de suínos em crescimento à adequada relação energia:proteína da ração.

Com relação à taxa de deposição de proteína (TDP) e à taxa de deposição de gordura (TDG) na carcaça, foi observado que o nível de proteína da ração influenciou $(\mathrm{P}<0,01)$ a TDP, que aumentou de forma linear segundo a equação: $\hat{Y}=3,46551$ $+3,47406 \mathrm{~PB}\left(\mathrm{r}^{2}=0,78\right)$, e não influenciou $(\mathrm{P}>0,10)$ a TDG, que apresentou valor médio de $73,4 \mathrm{~g} /$ dia. Semelhantemente aos resultados obtidos neste estudo, Donzele et al. (1992) e Hannas et al. (2000) não verificaram influência da nutrição protéica sobre a TDG na carcaça dos leitões, na fase inicial de crescimento. Variação da TDP na carcaça de suínos na fase inicial de crescimento, em razão do nível de lisina ou proteína na ração, também foi observada por Donzele et al. (1992) e Hannas et al. (2000).

A melhora gradativa ocorrida na $\mathrm{CA}$, entre os níveis de 17 e $20 \%$, pode, provavelmente, ser explicada pelo aumento linear na TDP, uma vez que a deposição de proteína agrega maior quantidade de água que a de gordura (Kyriazakis et al., 1994).

Ficou evidenciado, neste estudo, que os níveis de proteína da ração podem influenciar tanto o ganho de peso quanto à deposição de proteína, quando suínos, de 15 a $30 \mathrm{~kg}$ são mantidos em baixa temperatura.

\section{Conclusões}

Figura 3 - Conversão alimentar $(\mathrm{g} / \mathrm{g})$ de leitões de 15 a $30 \mathrm{~kg}$ mantidos em ambiente de baixa temperatura, em função do nível de proteína bruta da ração.

Figure 3 - Feed:gain ratio of pigs from 15 to $30 \mathrm{~kg}$, under low temperature environment, according to the dietary crude protein level.
O nível de $20 \%$ de proteína bruta na ração, associado a um consumo estimado de $10,7 \mathrm{~g}$ de lisina total diário, promoveu o melhor desempenho de suínos machos de 15 a $30 \mathrm{~kg}$, mantidos em ambiente de baixa temperatura.

R. Bras. Zootec., v.32, n.6, p.1690-1696, 2003 (Supl. 1) 


\section{Literatura Citada}

BERSCHAUER, F.; CLOSE, W.H.; STEPHENS, D.B. The influence of protein:energy value of the ration and levels of feed intake on the energy and nitrogen metabolism of the growing pig. British Journal of Nutrition, v.49, p.271$283,1983$.

BUFFINGTON, D.E.; COLAZZO-AROCHO, A.; CANTON, G.H. et al. Black globe-humidity index (BGHI) as comfort equation for dairy cows. Transaction of ASAE, v.24, p.711$714,1981$.

CURTIS, S.E. Enviromental management in animal agriculture: Ames: Iowa State University Press, 1983. $406 \mathrm{p}$.

DONZELE, J.L.; COSTA, P.M.A.; ROSTAGNO, H.S. et al. Efeito dos níveis de lisina na composição da carcaça de suínos de 5 a $15 \mathrm{~kg}$. Revista da Sociedade Brasileira de Zootecnia, v.21, p.1091-1099, 1992.

EDMONDS, M.S.; ARENTSON, B.E.; MENTE, G.A. Effect of protein levels and space allocations on performance of growing-finishing pigs. Journal of Animal Science, v.76, p. 814-821, 1998.

FERGUSON, N.S.; GOUS, R.M. The influence of heat production on voluntary food intake in growing pigs given proteindeficient diets. Journal of Animal Science, v.64, p.365$378,1997$.

FIALHO, E.T. Influência da temperatura ambiental sobre a utilização da proteína e energia em suínos em crescimento e terminação. In: SIMPÓSIO LATINO-AMERICANO DE NUTRIÇÃO DE SUÍNOS, 1994, São Paulo. Anais ... São Paulo: Colégio Brasileiro de Nutrição Animal, 1994. p.63.

FIALHO, E.T.; CLINE, T.R. Influence of environmental temperature and dietary protein levels on apparent digestibility of protein and amino acids and energy balance in growing pigs. In: VERSTEGEN, M.W.A., HUISMAN, J., HARTOG, L.A. (Eds.) Digestive physiology in pigs. Wageningen: Pudoc, 1994. p.132-138.

FRIENSEN, K.G.; NELSSEN, J.L.; GOODBAND, M.D. et al. Influence of dietary lysine on growth and carcass composition of hight-lean-growth gilts fed from 34 to 72 kilograms. Journal of Animal Science, v.72, p.1761-1770, 1994.

HANNAS, M.I. Aspectos fisiológicos e a produção de suínos em clima quente In: SILVA, I.J.O. (Ed.) Ambiência e qualidade na produção industrial de suínos. Piracicaba: Fundação de Estaudos Agrários "Luiz de Queiroz", 1999a. p.1-33.

HANNAS, M.I. Proteína bruta para suínos machos castrados mantidos em diferentes condições térmicas dos 15 as 30 kg. Viçosa, MG: Universidade Federal de Viçosa, 1999. 64p. (Mestrado em Zootecnia) - Universidade Federal de Viçosa, 1999b.

HANNAS, M.I.; OLIVEIRA, R.F.M.; DONZELE, J.L. et al. Proteína bruta para suínos machos castrados mantidos em ambiente de conforto térmico dos 15 aos $30 \mathrm{~kg}$. Revista Brasileira de Zootecnia, v.29, p.476-484, 2000.

HENRY, Y.; SÈVE, B. Feed intake and dietary amino acid balance in growing pigs with special reference to lysine, tryptophan and threonine. Pig News Information, v. 14, p. 35-43, 1993.
KYRIAZAKIS, I.; EMMANS, G.C. The effects of varying protein and energy intakes on the growth and body composition of pigs. 1. The effects of energy intake at constant, high protein intake. British Journal Nutrition, v.68, p.603-614, 1992.

KYRIAZAKIS, I.; DOTAS, D.; EMMANS, G.C. The effects of breed on the relationship between feed composition and the eficiency of protein utilization in pigs. British of Journal Nutrition, v.71, p.849-859, 1994.

NOBLET, J.; HENRY, Y.; DUBOIS, S. Effect of protein and lysine levels in the diet on body gain composition and energy utilization in growing pigs. Journal of Animal Science, v.72, p.344-354, 1987.

ORLANDO, U.A.D. Nível de proteína bruta da ração e efeito da temperatura ambiente sobre o desempenho e parâmetros fisiológicos de leitoas em crescimento. Viçosa, MG: Universidade Federal de Viçosa, 2001. 77p. Dissertação (Mestrado em Zootecnia) - Universidade Federal de Viçosa, 2001.

QUINIOU, N.; DUBOIS, S.; NOBLET, J. Voluntary feed intake and feeding behaviour of group-haused growing pigs are affected by ambient temperature and body weight. Livestock and Production Science, v.41, p.245-253, 2000.

RHODIMET Nutrition Guide. 2.ed. France: Rhône-Poulenc Animal Nutrition, 1993. 55p.

Rostagno, H.S.; SILVA, D.J.; COSTA, P.M.A. et al. Composição de Alimentos e Exigências Nutricionais de Aves e Suínos: Tabelas Brasileiras. Viçosa, MG: Universidade Federal de Viçosa, 1992. 59p.

SCHENCK, B.C.; STAHLY, T.S.; CROMWELL, G.L. Interactive effects of thermal environment and dietary amino acid and fat levels on rate and efficiency of growth of pigs housed in a conventional nursery. Journal of Animal Science, v.70, p.3803-3811, 1992.

SILVA, D.J. Análise de alimentos: métodos químicos biológicos. Viçosa, MG: Universidade Federal de Viçosa, 1990. 166p.

SOUZA, A.M. Exigências nutricionais de lisina para suínos mestiços, de 15 a 95 kg de peso. Viçosa, MG: Universidade Federal de Viçosa, 1997. 81p. Dissertação (Mestrado em Zootecnia) - Universidade Federal de Viçosa, 1997.

UNIVERSIDADE FEDERAL DE VIÇOSA - UFV. SAEG Sistema para Análises Estatísticas e Genéticas. Versão 7.1 Viçosa, MG. 1997. 150p. (Manual de utilização do programa).

VERSTEGEN, M.W.A.; DE GREEF, K.H. Influence of environmental temperature on protein and energy metabolism in pig production. In: SIMPÓSIO INTERNACIONAL DE NÃO RUMinantes, 1992, Lavras. Anais... Lavras: Sociedade Brasileira de Zootecnia, 1992. p.333. 